\title{
The ear under pressure
}

This issue of The Journal of Laryngology \& Otology has more of a focus on otology. The Archives of The Journal have a wealth of information going back in time to the journal's inception in 1887. A recent article by Flood and Kenyon reviewed The Journal's archive material on Ménière's disease, ${ }^{1}$ including an early description of endolymphatic sac surgery in 1927. Endolymphatic sac surgery is a contentious issue in Ménière's disease treatment. In the current issue, Locke and colleagues describe the surgical anatomy of the endolymphatic sac and suggest that the results of surgical decompression may be unpredictable because the sac is difficult to locate and decompress adequately. ${ }^{2}$ In another 'pressure-related' otological article, Mitchell-Innes and colleagues discuss air travellers' awareness of the preventability of otic barotrauma. ${ }^{3}$ Air travel is increasingly common, and it appears that although the majority of travellers suffer with otic barotraumas, very few of them are actually aware of simple prevention measures.

The Journal has very much an international outlook and has always been keen to publish articles relevant to ENT as the topics addressed in those articles present on the global stage. In particular, the Editors have accepted articles that highlight the problem of deafness and ear disease as a global issue. ${ }^{4-6}$ The effect of globalisation on health is a 'hot topic'. One feature of globalisation in developing countries is the migration of populations from a rural to an urban setting, so-called urbanisation. Shaheen and Nahar compare the incidence of chronic otitis media in rural and urban primary school children in Bangladesh, and find a significantly higher incidence in the rural communities. ${ }^{7}$ In addition, there were significant associations between the presence of chronic otitis media in children and parental occupation, housing type, family size, maternal education and bathing habit.

Facial pain is one of the most frequent reasons for patients to attend ENT clinics. Agius and colleagues followed up 240 patients with facial pain, with the majority being non-rhinogenic in nature. ${ }^{8}$ They found that the most effective long-term treatment for tension-type mid-facial pain and facial migraine was low-dose amitriptyline. Their findings support the notion that most patients with facial pain have 'medically unexplained symptoms'.

\section{ROBIN YOUNGS EDWARD FISHER Senior Editors}

References

1 Flood LM, Kenyon G. Concepts of Ménière's disease in the Archives of The Journal of Laryngology and Otology. J Laryngol Otol 2014;128:308-17

2 Locke RR, Shaw-Dunn J, O'Reilly BF. Endolymphatic sac surgical anatomy and transmastoid decompression of the sac for the management of Ménière's disease. J Laryngol Otol 2014;128: 488-93

3 Mitchell-Innes A, Young E, Vasiljevic A, Rashid M. Air travellers' awareness of the preventability of otic barotrauma. J Laryngol Otol 2014;128:494-8

4 Maile EJ, Youngs R. Quality of life measures in otitis media. J Laryngol Otol 2013;127:442-7

5 Fagan JJ, Stafford N, Youngs R. The global scope of ENT. J Laryngol Otol 2012;126:543

6 Chadha S. International Ear Care Day - 3rd March. J Laryngol Otol 2014;128:221-2

7 Shaheen MM, Nahar S. Comparison of chronic suppurative otitis media in rural and urban primary school children in Bangladesh. J Laryngol Otol 2014;128:499-503

8 Agius AM, Jones NS, Muscat R. Prospective three-year follow up of a cohort study of 240 patients with chronic facial pain. J Laryngol Otol 2014;128:518-26

9 Ullas G, McClelland L, Jones NS. Medically unexplained symptoms and somatisation in ENT. J Laryngol Otol 2013;127:452-7 